ROCZNIKI HUMANISTYCZNE

Tom LXVIII, zeszyt 8 - 2020

DOI: http://dx.doi.org/10.18290/rh.20688-9

MONIKA PLEWKO

\title{
ANÁLISIS DEL FENÓMENO DE PERSUASIÓN EN EL DISCURSO MEDIOAMBIENTAL DE JUAN PABLO II
}

\author{
ANALYSIS OF THE PERSUASION PHENOMENON \\ IN THE ENVIRONMENTAL DISCOURSE OF JOHN PAUL II
}

Abstract

This article constitutes a contrastive analysis of the discourse of John Paul II and precisely of the linguistic resources of persuasion that appear in a thematic type of his homilies. As research material, texts in two selected languages are used: Polish and Spanish, which deal only with the environmental issue. The objective of the article is to present some linguistic (rhetorical) resources of the persuasion phenomenon that appear in homilies of John Paul II. Our intention is to show, based on a series of concrete examples, what formal elements influence the persuasiveness of John Paul II's speech and how these resources vary across both languages.

Key words: John Paul II; homily; preach; persuasion; rhetoric.

\section{INTRODUCCIÓN}

El reto de este trabajo es presentar un estudio contrastado en el cual presentamos los recursos lingüísticos de persuasión en las homilías de Juan Pablo II. En la primera parte describimos el carácter de la persuasión y se presenta la retórica de las homilías. En la segunda parte se detallan los recursos lingüísticos de persuasión más comunes que aparecen en los textos analizados. En el presente artículo nos centramos en los elementos léxicos, morfo-

Monika Plewko, MA - Universidad Católica Juan Pablo II de Lublin, Facultad de Humanidades, Instituto de Lingüística, Departamento de Lingüística Románica; dirección de correspondencia: Al. Racławickie 14, 20-950 Lublin, Polonia; correo electrónico: monika.plewko@ gmail.com. ORCID: https://orcid.org/0000-0003-4504-5213.

Mgr Monika Plewko - Katolicki Uniwersytet Lubelski Jana Pawła II, Wydział Nauk Humanistycznych, Instytut Językoznawstwa, Katedra Językoznawstwa Romańskiego; adres do korespondencji: Al. Racławickie 14, 20-950 Lublin, e-mail: monika.plewko@gmail.com. ORCID: https://orcid.org/0000-0003-4504-5213. 
lógicos y sintácticos que influyen en el carácter persuasivo. Teniendo en cuenta los estudios anteriores sobre el carácter persuasivo de los sermones y del estilo de Juan Pablo II se establece una hipótesis que en los textos de la temática medioambiental, tanto en los textos de idioma polaco como español aparecen los recursos lingüísticos de persuasión.

La forma de hablar de Juan Pablo II fascina a muchos eruditos. En múltiples trabajos se intenta describir sus discursos y homilías. El estilo de su expresión es analizado muy a menudo por lingüistas y teóricos de la retórica.

Merino Dickinson ha elaborado un texto "Metáfora y tiempo narrativo en los discursos del papa Juan Pablo II", Jan Miodek (173-176) se centra en sus palabras favoritas, autores como Dorota Zdunkiewicz-Jedynak (Językowe środki) o Zagórska analizan la persuasión de los textos de Juan Pablo II.

Si bien las obras polacas o extranjeras mencionadas anteriormente tratan sobre el estilo de Juan Pablo II, no existen estudios de carácter comparativo polaco-español sobre el tema de persuasión.

Deseando caracterizar los recursos persuasivos que utiliza Juan Pablo II es preciso describir el carácter persuasivo de las homilías.

Antes de pasar al análisis empírico parece conveniente presentar el corpus. Hemos elegido a 15 homilías censados en las páginas que se citan en la parte bibliográfica. Los textos polacos cuentan con 15520 palabras gráficas en total, mientras que los españoles con 15520 palabras. Los discursos polacos de Juan Pablo II han sido extraídos de las páginas ZiBaTePa. Zintegrowana Bazy Tekstów Papieskich (www.nauczaniejp2.pl) y Opoka.org.pl (www.opoka.org.pl) y los españoles, por su parte, de la página La Santa Sede (www.vatican.va). Las homilías analizadas constituyen un corpus de tipo comparable, aunque no se trata de una muestra equilibrada ya que todas tratan sobre el tema de medio ambiente. A efectos del presente análisis los textos sometidos al análisis no se han sometido a ninguna diversificación. Nuestro reto ha sido estudiar el fenómeno de persuasión en los sermones medioambientales de Juan Pablo II, corpus temático que se inscribe en el perfil del presente número de la revista. Juan Pablo II ha sido el primer papa que ha prestado tanta atención al tema del medio ambiente. Podemos decir que ha creado su propio concepto en el que ha incluido cuestiones relacionadas con la preservación del planeta (Bołoz 117). Todos los textos fueron publicados durante el periodo de 1980-2003 y son del mismo género homilías. 


\section{LAS DEFINICIONES DE LA PERSUASIÓN Y LOS RECURSOS LINGÜÍSTICOS EN LA LENGUA POLACA Y ESPAÑOLA}

Existen muchas definiciones de la persuasión pero la que está en la base de nuestro estudio es la de Szymanek (228):

(...) perswazja to świadome użycie znaków i symboli, a zwłaszcza pisanego i mówionego słowa, obrazu itp. w celu wywarcia wpływu na czyjeś przekonania, postawy i decyzje: zdobycia czyjeś akceptacji lub przynajmniej przychylności dla proponowanych poglądów, sposobu zachowania, decyzji.

Persuasión es una función del lenguaje que abarca todos los aspectos de la lengua. Los elementos de la antigua retórica se usan ya en los primeros siglos del cristianismo. La retórica antigua, que sirve a las necesidades de la vida social, reconoce que las convicciones de los oyentes son su objetivo (Siwek). Por lo tanto, el "arte de hablar bellamente" (ars bene dicendi), como lo llama Quintilian, pasa a la historia como "el arte de la persuasión" (ars persuadendi).

Cabe señalar que la mayoría de los sermones hablan sobre qué hacer. Por eso la tarea principal del predicador es encontrar los motivos y presentarlos de tal manera que conmuevan la voluntad del oyente. Es importante mencionar que la homilía es un tipo dominante del discurso homilético que funciona después del Concilio Vaticano II. La palabra homilia viene de homilein "hablar fraternalmente" (Müller 15). Homilía representa entonces un discurso bilateral, que contrata de forma activa a dos partes. Constituye una parte integral de un oficio religioso (Waznak 3).

San Agustín señala que predicando Evangelio no sólo importa lo que decimos pero cómo lo decimos (Augustyn). El tema de la influencia persuasiva consciente es bastante complicado y delicado. También debe mencionarse, como señala Siwek que la persuasión utilizada adecuadamente no tiene nada que ver con la manipulación que deforma deliberadamente la realidad.

Este artículo presenta algunos medios lingüísticos de persuasión utilizados en las homilías de Juan Pablo II en polaco y español. Los fragmentos de discursos están seleccionados de las homilías medioambientales.

Tanto el idioma polaco como español disponen de un amplio abanico de recursos lingüísticos de persuasión. Es obvio que no podemos abordar todos los recursos, así que nos centramos en las herramientas de los recursos léxicos de persuasión (verbos de obligación), medios morfológicos de persuasión (formas de la 1 persona singular, 1 persona plural, 3 persona singular) y medios sintácticos de persuasión (el modo imperativo). 


\subsection{ReCURSOS LINGÜísticos DEL CARÁCter PERSUASIVO}

Al principio de nuestro artículo hemos mencionado las palabras de Aristóteles, que el orador solo a través de sus palabras puede causar la impresión de los oyentes (Siwek). También en las homilías la persuasión se realiza a través de las palabras que utiliza el orador. Entre las características de los textos persuasivos podemos enumerar entre varios: el uso de los superlativos o las palabras de generalización (Siwek 162). Zdunkiewicz-Jedynak (Językowe środki 126) aborda el tema de la persuasión de las homilías mencionando los recursos en el nivel léxico, morfológico y sintáctico. A continuación analizaremos algunos de los recursos que aparecen en las elegidas homilías. Nos centramos en los verbos de obligación para después pasar al análisis de las expresiones imperativas, el modo imperativo y la categoría verbal de persona.

\subsubsection{Verbos de obligación}

Los verbos de obligación son los que caracterizan a menudo los textos persuasivos. Se los utiliza frecuentemente en las homilías para influir a los creyentes utilizando, llamado por Zdunkiewicz-Jedynak ("Perswazyjność"), el vocabulario normativo que aborda los verbos tales como: musieć y trzeba o deber y hay que. Por una parte existen los verbos modales que se conjugan en un determinado modo, tiempo y persona (como musieć y deber). Por otra parte existen las expresiones impersonales que no se conjugan ni por persona, ni tiempo, ni modo. Cabe mencionar que tanto en la lengua polaca como española aparecen los verbos modales (el verbo musieć y deber) y las formas impersonales como: trzeba, należy en polaco y hay que en español. En nuestro estudio analizamos los verbos defectivos polacos que son más frecuentes que el verbo musieć. Dichos verbos defectivos en comparación con el verbo modal son más suaves y no expresan la obligación directa.

\subsubsection{Los verbos defectivos polacos}

Los verbos defectivos son los verbos que no cumplen con las reglas de conjugación, pueden conjugarse según la categoría de tiempo y modo, pero no de persona, número ni género. Los verbos defectivos no tienen infinitivo. Aunque no cumplen todos los criterios de los verbos, en las frases pueden funcionar como predicados. Frecuentemente están acompañados por los infinitivos. 
Entre los verbos defectivos en polaco podemos enumerar: trzeba, należy, nie można, nie wolno. Todas estas palabras llevan un elemento evaluativo. E1 remitente quiere dar a entender que algunas cosas son positivas o negativas y el interlocutor debería hacer lo que señala el remitente. El verbo trzeba es un verbo invariable, no reflexivo, impersonal (Strutyński 136). En el caso de este verbo, es posible crear formas que distinguen la categoría de tiempo y modo, por ejemplo: trzeba było, trzeba będzie. Con frecuencia las oraciones con dicho predicado expresan los preceptos morales básicos (ZdunkiewiczJedynak, "Językowe srodki" 153).

Otro verbo que sirve para expresar una obligación es el verbo należy, que es un verbo impersonal, una forma construida como la forma de un solo verbo personal de tercera persona. En comparación con el verbo musieć el verbo defectivo należy es una suave forma de expresar un deber. El remitente no dirige las palabras directamente al público, nadie siente el peso de tener que cumplir la obligación. También la forma negativa no está dirigida al público que no se siente atacado por el remitente.

\subsubsection{Los verbos de obligación españoles}

La lengua española, como la polaca, ofrece diferentes maneras de expresar una obligación. Sin embargo, no podemos estudiar todas las posibilidades y estamos obligados a elegir algunas de ellas. A continuación se abordarán tales casos como el verbo deber y los adjetivos necesario, urgente, preciso que junto con el verbo ser forman las expresiones: es necesario, es urgente, es preciso. Además existe en la lengua española la expresión impersonal hay que, que sirve para expresar una obligación y que corresponde a la palabra trzeba en polaco.

\subsubsection{El verbo deber}

El verbo deber, que va con el infinitivo, expresa la obligación o la obligación unida a la intención del hablante. Los valores semánticos más comunes de esta perífrasis son los de obligación activa (Tú debes trabajar más) y de obligación pasiva (Las flores deben ser cuidados) (Gómez Torrego 3349). El verbo deber que va junto con el infinitivo puede indicar la obligación originada del deseo del hablante sobre la necesidad de realizar un hecho.

\subsubsection{Expresiones imperativas (es necesario, es urgente, es preciso)}

El uso de las palabras imperativas es común en la comunicación persuasiva. Como escribe Aleksy Awdiejew ("Systemowe środki perswazji” 77; Gra- 
matyka 145) el uso de tales lexemas permite de manera eficaz sugerir al público una opinión en forma de las creencias, facilita expresar al emisor su actitud acerca de los fenómenos u objetos. Según Jacques Moeschler las expresiones imperativas son entendidas como lexemas tales como los sustantivos, verbos, adjetivos o proverbios. En el presente estudio nos concentramos en los adjetivos imperativos en los discursos de Juan Pablo II: es preciso, es urgente, es necesario. Cabe destacar que la lengua polaca dispone también de las palabras imperativas, entre ellas podemos enumerar: jest konieczne, jest ważne.

\subsubsection{E1 modo imperativo}

Las frases imperativas son las que sirven para expresar una orden, petición o prohibición. La naturaleza de la inducción se realiza a través del modo imperativo pero existen las situaciones cuando se debería evitarlo o se lo considera desaconsejable. Especialmente a causa del interlocutor que puede sentirse ofendido. De todas maneras, el modo imperativo es una herramienta más simple de la persuasión (Zdunkiewicz-Jedynak, Językowe środki).

\subsubsection{La función persuasiva de la categoría verbal de persona}

La categoría apropiada de la persona verbal es un elemento inseparable de los textos retóricos, incluidos los sermones. Mediante el uso de las formas personales, se realiza el carácter del diálogo del sermón (Przymuszała 57). En este artículo se analizan las formas verbales personales más comunes: la primera forma singular y plural, y la tercera forma singular.

\subsubsection{La primera persona plural}

La primera persona plural crea el sentimiento de amabilidad y unión, el remitente (el sacerdote en el caso de los sermones) acerca hacia él al grupo, es el recibidor de las recomendaciones. Gracias a la forma verbal de la primera persona plural no se crea la barrera entre él y los oyentes (Kępka 157).

\subsubsection{La primera persona singular}

La primera persona singular, mencionada anteriormente, la que debilita el modo imperativo, también es usada frecuentemente como herramienta lingüística del carácter persuasivo. Gracias a la primera forma singular de las formas verbales se crea el carácter del diálogo de la homilía. El uso de la primera persona del singular sirve para contactar con los oyentes. El remitente no esconde sus creencias, se expresa de forma abierta, comparte sus pensamientos, opiniones. Dirige sus sentimientos hacia los oyentes (Kępka 157). 


\subsubsection{La tercera persona singular}

Según Zdunska-Jedynak (Językowe środki) la introducción de la tercera persona plural está conectada con la creación de la categoría del enemigo. La tercera forma verbal se refiere a una persona que está fuera del acto comunicativo, al contrario a la segunda persona singular (Wielgosz).

\section{ANÁLISIS CONTRASTIVO DE LOS RECURSOS LINGÜÍSTICOS DE PERSUASIÓN EN LAS ELEGIDAS HOMILÍAS DE JUAN PABLO II}

\subsection{Introducción}

En la siguiente parte analizaremos los ejemplos de los elementos lingüísticos de carácter persuasivo polacos y españoles. Gracias a este estudio podemos comparar los recursos: su intensidad y frecuencia.

Al principio queremos analizar los verbos de obligación que frecuentemente aparecen en los textos analizados. A base de nuestro análisis encontramos los verbos defectivos polacos: trzeba y należy y el verbo español: deber. A continuación, pasaremos a la descripción de las expresiones imperativas, el modo imperativo y las formas personales de los verbos.

\subsubsection{Los verbos de obligación en los textos polacos}

El verbo de obligación que aparece con mucha frecuencia en los textos analizados es el verbo defectivo trzeba que cuenta con 32 ocurrencias. En los analizados ejemplos el verbo expresa una obligación general:

(1) Dlatego też uznać trzeba, że wszelkie działania, które nie uwzględniają prawa Boga do swego dzieła, jak i prawa człowieka obdarowanego przez Stwórcę, sprzeciwiają się przykazaniu miłości. ([PL7] 3)

(2) Trzeba więc pobudzać i popierać nawrócenie ekologiczne, które w ostatnich dziesięcioleciach sprawiło, że ludzkość stała się bardziej wrażliwa na niebezpieczeństwo katastrofy, do jakiej zmierzaliśmy. ([PL8] 7)

El verbo należy aparece 46 veces en los textos. Cabe señalar que en todos los ejemplos el verbo należy aparece en el tiempo presente. Abajo presentamos algunos ejemplos:

(3) Należy już dziś podjąć solidarne i odpowiedzialne przeciwdziałanie, zanim spustoszenie naszej planety stanie się nieodwracalne. ([PL2] 10) 
(4) Kształtuje się w ten sposób świadomość ekologiczna, której nie należy tłumić, a przeciwnie trzeba sprzyjać jej pogłębianiu i dojrzewaniu, tak aby mogła znaleźć wyraz w konkretnych programach i inicjatywach. ([PL6] 7)

\subsubsection{Los verbos de obligación - el español}

\section{Verbo deber}

En el texto analizado encontramos 52 ocurrencias del verbo deber. La mayoría de los casos se refieren a la tercera forma singular, lo que puede indicar que la necesidad de cumplir las obligaciones recae sobre el anteriormente mencionado "adversario" o la persona que no participa en el diálogo entre el orador y el público.

(5) Esa ley establece cierto orden interior que el hombre encuentra y que debe conservar. ([ES6] 12)

Además aparecen 20 ocurrencias de la tercera forma plural. Tal como sucede en el caso de la tercera persona singular, la tercera forma de plural es usada para no destinar directamente las obligaciones a los oyentes:

(6) Estas iniciativas deben apoyarse en una concepción del mundo que tiene al hombre como centro y que sabe aceptar la variedad de las condiciones históricas y ambientales (...). ([ES4] 5)

(7) Los cristianos siempre deben estar dispuestos a asumir juntos su responsabilidad que lleva al vasto campo de cooperación ecumenica e interreligiosa. ([ES1] 7).

(8) (...) los que tienen responsabilidad. Deben preparar programas para la conservación del medio ambiente y velar por su realización eficaz. ([ES6] 13).

\subsection{El modo imperativo - el polaco y el español}

\section{Según Zdunkiewicz-Jedynak (Językowe środki 93):}

[tryb rozkazujący to] najprostszy sposób kształtowania w odbiorcy dyspozycji do określonej aktywności (...). Zdań ze wskaźnikiem gramatycznym w postaci trybu rozkazującego jest $\mathrm{w}$ homiliach papieskich bardzo dużo. Występują praktycznie w każdej homilii. Na ogół jednak poprzedzają je wyrazy, konstrukcje osłabiające moc zdań rozkaźnikowych, wprowadzające klimat zachęty, życzliwego ostrzeżenia, nie zaś silnej presji - nakazu czy zakazu (80\%).

Como mencionamos anteriormente el modo imperativo es la manera más fácil y convencional del proceso de la persuasión. Pero a menudo la forma del imperativo está reemplazada por las formas de la primera persona de los 
verbos: $\dot{z} y c z y c ́$, zachęcać, przypominać. Este es el caso de los textos analizados. Aparecen las formas de la primera persona singular que expresan el modo imperativo.

En el caso de los textos polacos no encontramos las formas del modo imperativo. Como en el material español, en los textos polacos anotamos formas de la primera persona singular. Existen 20 ocurrencias, entre ellas destacamos:

(9) Zachęcam wszystkich, by włączyli się w tę jednogłośną modlitwę do Boga (...) ([PL8] 6)

En el caso de los textos españoles tampoco encontramos las formas del modo imperativo.Como en el material polaco, en los textos españoles anotamos formas de la primera persona singular. Encontramos 25 ocurrencias, entre ellas los siguientes ejemplos:

(10) (...) me dirijo a cuantos tienen la responsabilidad (...) a no olvidar el deber de protegerlo contra la destrucción ecológica. ([ES6] 4)

(11) (...) pido al Señor que os colme de las fuerzas espirituales que necesitáis. ([ES4] 11)

\subsection{Formas personales de los verbos}

En esta parte de nuestro estudio queremos analizar los ejemplos del uso de las formas personales de los verbos que poseen el carácter persuasivo. Entre las formas destacamos: la primera persona singular, la primera persona plural y la tercera persona singular.

\subsubsection{Primera persona singular - polaco}

Vamos a analizar el uso de la primera persona singular. En las homilías polacas encontramos 44 casos de las formas de la primera persona singular. Como se ha mencionado anteriormente la forma de primera persona singular crea el sentimiento de cercanía, hace que el remitente del mensaje parezca estar cerca de los interlocutores, muestra su preocupación:

(12) Jeżeli dziś mówię o tej świętości i godności, to czynię to w duchu dziękczynienia Bogu (...) a równocześnie czynię to $\mathrm{w}$ duchu troski o zachowanie dobra i piękna (...). ([PL7] 2) 
La forma de la primera persona singular, que aparece con más frecuencia es: pragne que viene del verbo pragnać. En el texto existen 20 ocurrencias. Abajo presentamos un ejemplo:

(13) Tu pragnę bodaj dotknąc bardzo dziś aktualnej w całym świecie sprawy ochrony zagrożonego środowiska naturalnego. ([PL1] 14)

En comparación con otras formas personales la primera persona singular tiene el menor valor persuasivo pero sigue influyendo al interlocutor porque estimula su atención e incrementa su curiosidad. Los ejemplos de las formas de la primera persona singular se refieren a las opiniones del orador que expresa sus pensamientos o juicios:

(14) Wiem, że biskupi polscy wyrażali taki niepokój już przed dziewięciu laty, zwracając się do wszystkich ludzi dobrej woli w liście pasterskim na temat ochrony środowiska. ([PL7] 24)

Los verbos que se refieren a la acción de hablar son: mówię (9), powtarzam (4), wyrażam (4). Todos los ejemplos de las formas están en el presente de modo indicativo. Abajo presentamos un ejemplo:

(15) Mówię to tu, na białostockiej ziemi, która należy do jednej z najpiękniejszych w Polsce, ze wspaniałą Puszczą Białowieską. Ale zwracam się do wszystkich ludzi w całej Ojczyźnie. ([PL4] 9)

\subsubsection{Primera persona del singular - español}

En los textos españoles encontramos 24 casos de los verbos en la primera persona singular. Casi todas las formas están en el presente de modo indicativo, hay un ejemplo del verbo en primera persona singular en pretérito perfecto compuesto. Tal como en los textos polacos la forma más frecuente es: deseo del verbo desear que expresa expectativas y esperanzas del orador. Cabe señalar que la forma verbal deseo está seguida por los infinitivos.

(16) Deseo dirigirme directamente a mis hermanos y hermanas (...) para recordarles la importante obligación de cuidar toda la creación. ([ES2] 12)

(17) Por eso, al comienzo de este Mensaje, deseo recordar la narración bíblica de la creación (...). ([ES2] 13)

Los verbos que se refieren a la acción de hablar son: Me he referido, dirijo, hablo y repito. Cabe señalar que todas las frases que llevan las formas de la primera persona singular son las frases afirmativas. 


\subsubsection{Primera persona del plural - el polaco}

En los textos analizados encontramos relativamente pocos ejemplos de la primera persona plural, en concreto 7 casos. Mediante la primera persona plural el orador abarca todos "participantes" del diálogo, que es la homilía. El orador se considera a sí mismo un elemento del público:

(18) Jeżeli mówimy o odpowiedzialności przed Bogiem, to mamy świadomość, że tu już nie chodzi tylko o to, co we współczesnym języku zwykło się nazywać ekologią. ([PL7] 3).

\subsubsection{Primera persona plural - el español}

En la muestra española encontramos 54 ejemplos de la primera persona plural. En los ejemplos notamos la intención del orador de crear un ambiente de la unión y la responsabilidad común por el medio ambiente:

(19) Cuando sacrificamos nuestra vida y compartimos nuestros bienes, ganamos la vida en abundancia y enriquecemos al mundo entero. ([ES2] 8).

\subsubsection{Tercera persona singular - el polaco}

El uso de la tercera persona del singular le sirve al predicador para referirse a la persona al conjunto general de las personas. Al contrario de las primeras personas del singular o del plural, en el caso de la tercera persona singular no existe el carácter del diálogo de la homilía. La tercera persona no participa en el acto comunicativo de la homilía. En las frases recogidas en los textos encontramos las referencias al hombre, a menudo el portador de antivalores:

(20) (...) kiedy to człowiek sam stał się niszczycielem środowiska naturalnego. ([PL5] 20).

(21) (...) głęboką przyczyną wszelkich zamachów na przyrodę jest nieład moralny i pogarda, jaką człowiek żywi do człowieka. ([PL6] 18).

\subsubsection{Tercera persona singular - el español}

Después de haber analizado los ejemplos del uso de la tercera persona del singular en polaco, cabe realizar un estudio de los casos en las homilías españolas. Hemos anotado 8 casos del uso de la tercera forma singular que se refiere al hombre. En los ejemplos utilizados por Juan Pablo II habla de manera positiva del hombre, no sugiere la existencia de un adversario. Abajo presentamos unos ejemplos: 
(22) El hombre contemporáneo se siente impulsado a plantear una cuestión fundamental, que puede definirse ética y, a la vez ecológica. ([ES1] 12)

(23) El hombre es el único responsable de las consecuencias de su acción. ([ES4] 6).

(24) El hombre está llamado a cultivar y dominar la tierra que Dios le ha confiado (...) $([\mathrm{ES} 3] 4)$

En otros ejemplos notamos que el predicador se refiere a una persona o a un grupo creando un especie del adversario:

(25) No es posible que una persona o un grupo determine sus propias exigencias con respecto al medio ambiente, ignorando al resto de la humanidad. ([ES1] 8).

\subsection{Los adjetivos imperativos}

\subsubsection{Los adjetivos imperativos - polaco}

El siguiente recurso persuasivo utilizado en los discursos de Juan Pablo II es el adjetivo imperativo que junto con el verbo być o istnieć forma las expresiones: istnieje silna potrzeba, konieczne jest, ważne jest. En los textos polacos encontramos solo 9 ejemplos de este tipo, abajo presentamos uno de ellos:

(26) Istnieje więc silna potrzeba kształtowania postawy odpowiedzialności ekologicznej (...) ([PL3] 22).

Notamos que en vez de los adjetivos valorativos en los textos analizados polacos se utiliza más los verbos defectivos należy o trzeba.

\subsubsection{Los adjetivos imperativos - español}

En los textos españoles podemos observar 35 ejemplos de este recurso. Cabe señalar que en la mayoría de los casos, el adjetivo está acompañado por los verbos en infinitivo ( 25 casos). Abajo presentamos algunos ejemplos:

(27) (...) es necesario igualmente desarrollar su sentido cívico y su atención a los demás (...). ([ES4] 15)

(28) Es preciso añadir también que no se lograra el justo equilibrio ecológico si no se afrontan directamente las formas estructurales de pobreza (...). ([ES2] 17) 


\section{CONCLUSIONES}

En el resumen de análisis de los recursos de persuasión llegamos a la conclusión que en cuanto a las expresiones de obligación, en los textos españoles predomina el verbo deber (52 ocurrencias) y las expresiones imperativas (es urgente, es importante, es preciso) que nos dan 35 casos.

En los textos polacos en cuanto a las expresiones de obligación predominan los verbos defectivos (należy y trzeba). Cabe señalar que en todo el corpus polaco las formas del verbo musieć aparecen tan solo 17 veces.

Tabla 1.

\begin{tabular}{c|c|c} 
LENGUA & EXPRESIÓN DE OBLIGACIÓN & N. DE CASOS \\
\hline español & deber & 52 \\
\hline & es+necesario/preciso/urgente & 35 \\
\hline Polaco & trzeba & 32 \\
\hline & należy & 46
\end{tabular}

Es más, el análisis nos permite observar que en ninguna lengua aparece el modo imperativo. Dicho modo imperativo está sustituido por las formas de la primera forma singular de los verbos: pragnać, zachęcać, zwracać się y desear, invitar, pedir.

En el resumen de análisis de los recursos de persuasión llegamos a la conclusión que tanto en los textos españoles como polacos predominan las formas de la primera ( 54 casos en español y 44 en polaco) o de la tercera persona singular (82 casos en el corpus español y 79 en el polaco). La primera persona plural aparece en 39 ocurrencias en los textos españoles analizados y en 28 en los polaco); escasamente o nunca aparecen formas de la segunda persona singular o plural:

Tabla 2.

\begin{tabular}{c|c|c} 
PERSONA GRAMATICAL & LENGUA ESPAÑOLA & LENGUA POLACA \\
\hline yo (ja) & 54 & 44 \\
\hline nosotros (my) & 39 & 28 \\
\hline el/ella (on/ona) & 82 & 79
\end{tabular}


Al contemplar los resultados del análisis se puede constatar que tanto en español como en polaco, en los discursos analizados predominan recursos persuasivos similares que no presentan ninguna diferencia desde el punto de vista puramente formal, como es el caso de las expresiones de obligación.

\section{BIBLIOGRAFÍA}

Augustyn, święty. De doctrina christiana (O nauce chrześcijańskiej). Tłum. J. Sulowski. Instytut Wydawniczy Pax, 1989, pp. 45-49.

Awdiejew, Aleksy. "Systemowe środki perswazji”. Manipulacja w języku, red. Piotr Krzyżanowski y Paweł Nowak, Wydawnictwo UMCS, 2004.

Awdiejew, Aleksy. Gramatyka interakcji werbalnej. Wydawnictwo UJ, 2007.

Bołoz, Wojciech. Kościót i ekologia. W obronie człowieka i środowiska naturalnego. Homo Dei, 2010.

Dickinson, Merino. "Metáfora y tiempo narrativo en los discursos del papa Juan Pablo II". Nueva Stylo, núm. 2, 1999, pp. 75-90

Gómez Torrego, Leonardo. "Los verbos auxiliares. Las perífrasis verbales de infinitivo". Gramática descriptiva de la lengua española, red. Ignacio Bosque y Violeta Demonte, vol. 1-3, Espasa, 1999, p. 3349.

Kępka, Izabela. "Językowe środki perswazji w polskich kazaniach katolickich od oświecenia do czasów współczesnych: na wybranych przykładach". Język - szkoła - religia, 4, 2009, pp. 152-161.

Korolko, Mirosław. Sztuka retoryki. Przewodnik encyklopedyczny. Wiedza Powszechna, 1990,

Miodek, Jan. “Osobliwości stylu Jana Pawła II”. Język Polski, nr 3, 1984, pp. 173-176.

Moeschler, Jacques. Modelisation du dialogue. Représentation de l'inférence argumentative. Hermes Science Publications, 1989.

Müller, Klaus. Homiletyka na trudne czasy. Tłum. Magdalena Mijalska, Wydawnictwo M, 2003.

Pilch, Zygmunt. Zagadnienia języka i stylu w kaznodziejstwie. Seminarjum Duchowne w Kielcach, 1923.

Pisarek, Walery. Retoryka dziennikarska. RSW Prasa-Książka-Ruch, 1975.

Przymuszała, Lidia. Struktura i pragmatyka „Postylli” Samuela Dambrowskiego. Wydawnictwo Uniwersytetu Opolskiego, 2003.

Siwek, Gerard. Przepowiadać skuteczniej. Elementy retoryki kaznodziejskiej. Homo Dei, 1992,

Szymanek, Krzysztof. Sztuka argumentacji. Słownik terminologiczny. Wydawnictwo Naukowe PWN, 2001

Strutyński, Janusz. Gramatyka Polska. Tomasz Strutyński, 1997

Vásquez-Rocca, Liliana, y Magaly Varas. "Usos de estrategias persuasivas en el discurso religioso digital de católicos, protestantes y testigos de Jehová.” Estudios del Discurso vol.4, núm. 2, 2018, pp. 94-126. Doi: 10.30973/esdi/2018.4.2/6.

Waznak, Robert P. An Introduction to the homily. Liturgical Press, 1998.

Wielgosz, Małgorzata Maria. Análisis pragmalingüistico de sermones en base a textos en español $y$ en portugués. Tesis doctoral. UAM, 2017. 
Zagórska, Katarzyna. "Polskie homilie Jana Pawła II - rekonesans badawczy”. Poznańskie Studia Polonistyczne Seria Językoznawcza, t.18 (38), z.1, 2011, pp. 57-74.

Zdunkiewicz-Jedynak, Dorota. “Językowe środki perswazji w homiliach (na przykładzie tekstów Jana Pawła II)”. Język a Kultura, t. 4, 1991, pp. 149-158.

Zdunkiewicz-Jedynak, Dorota. "Perswazyjność tekstów kaznodziejskich”. Więź, núm. 9, 1993, pp. 51-55.

Zdunkiewicz-Jedynak, Dorota. Językowe środki przekazu w kazaniu. Wydawnictwo „Poligrafia Salezjańska”, 1996.

\section{CORPUS}

\section{LOS DISCURSOS DE JUAN PABLO II EN VERSIÓN POLACA (PL)}

[PL1] "Przemówienie do Przedstawicieli Świata Nauki", 9.06.1987, Lublin. ZiBaTePa. Zintegrowana Baza Tekstów Papieskich, www.nauczaniejp2.pl/dokumenty/wyswietl/ id/677. Fechas de acceso $10.06-17.08 .2020$.

[PL2] "Rozważania podczas Czuwania Modlitewnego", 19.08.1989, Santiago de Compostela. ZiBaTePa. Zintegrowana Baza Tekstów Papieskich, nauczaniejp2.p1/ dokumenty/wyswietl/ id/669. Fechas de acceso 10.06-17.08.2020.

[PL3] “Orędzie na Światowy Dzień Pokoju”, 8.12.1989, Vaticano. EKAI, ekai.pl/ dokumenty/ oredzie-na-swiatowy-dzien-pokoju-1989/. Fechas de acceso: 10.06 - 17.08. 2020.

[PL4] "Homilia w czasie mszy św. beatyfikacyjnej Matki Bolesławy Lament", 5.06.1991, Białystok. Opoka.org.pl, opoka.org.pl/biblioteka/W/WP/jan_pawel_ii/homilie/20 bialy stok_0506 1991.html. Fechas de acceso 10.06 - 17.08.2020.

[PL5] "Rozważania podczas Czuwania Modlitewnego", 14.08.1993, Denver. ZiBaTePa. Zintegrowana Baza Tekstów Papieskich, www.nauczaniejp2.pl/dokumenty/wyswietl/id/681. Fechas de acceso: $10.06-17.08 .2020$

[PL6] "Spotkanie Czterech Pokoleń na stadionie Azteków", 25.01.1999, Meksyk. Opoka.org.pl, opoka.org.pl/ biblioteka/W/WP/jan_pawel_ii/przemowienia/meksyk_25011999. html. Fechas de acceso $10.06-17.08 .2020$.

[PL7] "Liturgia Słowa", 12.06.1999, Zamość. Opoka.org.pl, opoka.org.pl/biblioteka/W/WP/ jan_pawel_ii/ przemowienia/zamosc_12061999.html. Fechas de acceso 10.06 - 17.08. 2020 .

[PL8] “Audiencja Generalna”, 17.01.2001, Vaticano. Opoka.org.pl, opoka.org.pl/ biblioteka/ W/ WP/jan_pawel_ii/audiencje/ag_17012001.html. Fechas de acceso 10.06-17.08.2020.

\section{LOS DISCURSOS DE JUAN PABLO II EN VERSIÓN ESPAÑOLA (ES)}

[ES1] “Audiencia General”, 8.12.1989, Vaticano. La Santa Sede, www.vatican.va/content/ john-paulii/es/audiences/1989/documents/hf_jp-ii_aud_19891206.html. Fechas de acceso 10.06 17.08.2020.

[ES2] “XXIII Jornada Mundial de la Paz", 1.01.1990, Vaticano. La Santa Sede, www. vatican.va/content/john-paul-ii/es/messages/peace/documents/hf_jp-ii_mes_19891208_ xxiii-world-day-for-peace.html. Fechas de acceso 10.06 - 17.08.2020.

[ES3] "Jornada Mundial del Medio Ambiente", 7.05.1996, Vaticano. La Santa Sede, www. vatican.va/content/john-paul-ii/es/speeches/1996/june/documents/hf_jp-ii_spe_19960607_ ambiente.html. Fechas de acceso 10.06 - 17.08.2020.

[ES4] "La Asamblea Plenaria de la Academia Pontifica de Ciencias", 12.03.1999, Vaticano. La 
Santa Sede, www.vatican.va/content/john-paul-ii/es/speeches/2002/november/ docu ments/ hf_jp-ii_spe_20021111_academy-sciences.html. Fechas de acceso 10.06-17.08.2020

[ES5] "Homilía", 5.06.1999, Gdańsk. La Santa Sede, www.vatican.va/content/john-paul-ii/ es/travels/1999/documents/hf_jp-ii_hom_19990605_gdansk.html. Fechas de acceso 10.06 17.08.2020.

[ES6] "Viaje Apostólico a Polonia", 12.06.1999, Zamość. La Santa Sede, w2.vatican.va/ content/john-paul-ii/es/homilies/1999/documents/hf_jp-ii_hom_19990612_zamosc.html. Fechas de acceso $10.06-17.08 .2020$.

[ES7] "V Simposio sobre el Medio Ambiente", 27.05.2003, Vaticano. La Santa Sede, w2. vatican.va/content/john-paul-ii/es/speeches/2003/june/documents/hf_jp-ii_spe_20030 611_bartholomaios-i.html. Fechas de acceso 10.06 - 17.08.2020.

\section{ANÁLISIS DEL FENÓMENO DE PERSUASIÓN EN EL DISCURSO MEDIOAMBIENTAL DE JUAN PABLO II}

\section{Resumen}

El presente texto constituye un análisis contrastivo del discurso de Juan Pablo II y precisamente de los recursos lingüísticos de persuasión que aparecen en un tipo temático de sus homilías. Como material de investigación se utilizan los textos en dos lenguas seleccionadas: polaco y español que tratan únicamente sobre el tema medioambiental. El objetivo del artículo es presentar algunos recursos lingüísticos (retóricos) del fenómeno de persuasión que aparecen en homilías de Juan Pablo II. Nuestra intención es mostrar, a base de una serie de ejemplos concretos, qué elementos formales influyen en el carácter persuasivo del discurso de Juan Pablo II y cómo varían dichos recursos a través de ambas lenguas.

Palabras clave: Juan Pablo II; homilía; predicación; persuasión; retórica.

\section{ANALIZA ZJAWISKA PERSWAZJI \\ W DYSKURSIE ŚRODOWISKOWYM JANA PAWŁA II}

Streszczenie

Niniejszy tekst stanowi analizę porównawczą przemówień Jana Pawła II, w szczególności językowych środków perswazji, które występują się w homiliach tematycznych. W tym celu został stworzony korpus tekstów w dwóch językach - polskim i hiszpańskim, których treść dotyczy m.in. środowiska naturalnego, a następnie zostały zestawione wybrane środki językowe o wartościach perswazyjnych, które w nich występują. Na podstawie konkretnych przykładów Autorka usiłuje wykazać, jakie formy gramatyczne i leksykalne wpływają na perswazyjny charakter przemówień Jana Pawła II oraz jakie różnice występują w ich użyciu w obydwu językach.

Słowa kluczowe: Jan Paweł II; homilia; kazanie; perswazja; retoryka. 